\title{
PERBEDAAN LIKUIDITAS SAHAM SEBELUM DAN SETELAH PENERAPAN KEPUTUSAN PERUBAHAN SATUAN PERDAGANGAN \\ (Studi Pada Emiten Di JII) ")
}

\author{
Mirza Dewi Riskyta \\ Mahasiswa Program StudiS I Ekonomi Islam-Fakultas Ekonomi dan Bisnis-Universitas \\ AirlanggaEmail: mirzadewi30@gmail.com \\ Leo Herlambang \\ Departemen Ekonomi Syariah-Fakultas Ekonomi dan Bisnis-Universitas \\ AirlanggaEmail: leo.herlambang@gmail.com
}

\begin{abstract}
:
Application of unit trade change decision is one that can be used as balance information for the investors to take an investment decision. Investors must be able to analyse the signal of any information regarding the application. That signal can change of supply and demand's shares. This study aims to find out the reaction of stock liquidity on application of unit trade change decision indicated by the difference of Trading Volume Activity (TVA) and Transaction Frequency Activity (TFA) on before and after the application of trade change decision. This study use event study approach held on 30 emiten of stock listed on Indonesia Stock Exchange period December 2013 - May 2014. This study use observation period for 11 days, are $t-5$ (five days before the application), t-0 (event date), and $t+5$ (five days after the application). Hypothesis test use paired t-test. The result based on statistical test with significance level $(a)=5 \%$ produce probability value 0.599 for TVA and 0.121 for TFA. Based on these result, it can be concluded that there is no significant difference between TVA and TFA on before and after the application of trade change decision.
\end{abstract}

Keywords: Unit Trade Change Decision, Trading Volume Activity, Transaction Frequency Activity.

\section{PENDAHULUAN}

Sistem keuangan syariah kini mulai berkembang di Indonesia. Hal ini ditandai dengan munculnya lembaga keuangan yang menerapkan prinsip syariah dalam operasional. Salah satu lembaga kevangan yang menerapkan prinsip syariah yaitu pasar modal. Di Indonesia pasar modal syariah diresmikan pada tanggal 13 dan 14 Maret 2003 oleh Bapepam-LK dan DSN-MUI. Dengan adanya peresmian pasar modal syariah membuat investor muslim tidak lagi ragu untuk berinvestasi di pasar modal.

Walaupun pasar modal syariah baru terbentuk, namun saham syariah telah lebih dulu dikenal olah masyarakat
Indonesia. Hal ini terjadi karena pada tanggal 3 Juli 2000 BEl bekerjasama dengan PT Danareksa Investment Management meluncurkan JII (Jakarta Islamic Index) (Hartono, 2013:131). Dalam JII terdapat 30 saham yang telah memenuhi syarat sebagai saham syariah.

Dalam pengambilan keputusan investasi seorang investor harus mempertimbangkan informasi yang beredar di pasar modal. Salah satu informasi yang baru-baru ini berkembang yaitu adanya perubahan satuan perdagangan efek bersifat ekuitas. Satuan perdagangan efek yang dulu sebesar 500 lembar kini diubah menjadi 100 lembar.

1) Jurnal ini merupakan bagian dari Skripsi yang ditulis oleh (Mirza Dewi Riskyta; 04111 14045) yang diuji pada 9 Februari 2015. 
Adanya informasi tersebut investor harus dapat menganalisis apakah informasi tersebut merupakan good news atau bad news. Jika informasi tersebut good news maka investor akan membeli saham, begitu juga sebaliknya (Sukmaningrum, 2009:5). Adanya reaksi jual atau beli dari investor akan mempengaruhi tingkat likuiditas saham di pasar modal, dengan proksi TVA (Trading Volume Activity) dan TVA (Transaction Frequency Activity).

Berdasarkan uraian yang telah dijelaskan, maka penulis dapat merumuskan dua masalah yang akan diteliti. Yang pertama apakah terdapat perbedaan TVA yang signifikan antara sebelum dan setelah penerapan keputusan perubahan satuan perdagangan? Sedangkan yang kedua apakan terdapat erbedaan TFA yang signifikan antara sebelum dan setelah penerapan keputusan perubahan satuan perdagangan?

Adapun tujuan penelitian ini yaitu untuk mengetahui apakah terdapat perbedaan TVA yang signifikan antara sebelum dan setelah penerapan keputusan perubahan satuan perdagangan dan untuk mengetahu apakah terdapat perbedaan TFA yang signifikan antara sebelum dan setelah penerapan keputusan perubahan satuan perdagangan.

\section{LANDASAN PUSTAKA}

Islam menganjurkan umatnya untuk berinvestasi sesuai syariat islam. Hal ini didasarkan pada hadits yang artinya "Ingatlah, Barangsiapa menjadi wali anak yatim yang memiliki harta, hendaklah dia menggunakannya berbisnis (keuntungannya) untuk anak yatim, dan jangan membiarkan harta itu dimakan oleh sedekah (zakat)". (HR Baihaqi).

Tandelilin (2001:4) mengartikan investasi sebagai komitmen atas sejumlah dana atau sumber daya lain yang dilakukan pada saat ini dengan tujuan untuk mendapatkan sejumlah keuntungan dimasa mendatang. Definisi lain dikemukakan oleh Bambang (2007:130) bahwa investasi adalah pengeluaran modal untuk pembelian aset fisik seperti pabrik, mesin, peralatan dan persediaan, yaitu merupakan bentuk dari investasi fisik atau rill.

Dalam islam keberhasilan suatu investasi ditentukan oleh kehendak Allah SWT, seperti yang tertuang dalam Q.S. Luqman 34 yang berbunyi:
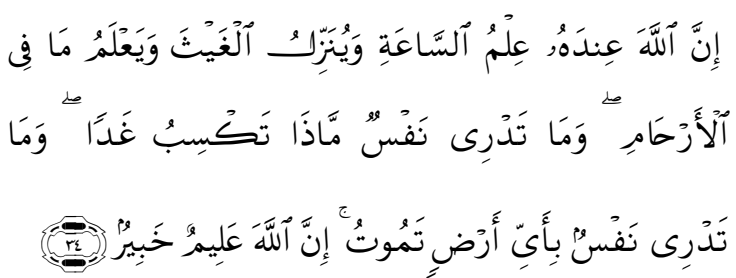

Artinya: "Sesungguhnya Allah, hanya pada sisi-Nya sajalah pengetahuan tentang hari Kiamat; dan Dia-lah yang menurunkan hujan, dan mengetahui apa yang ada dalam rahim. dan tiada seorangpun yang dapat mengetahui (dengan pasti) apa yang akan diusahakannya besok[1187]. dan tiada seorangpun yang dapat mengetahui di bumi mana Dia akan mati. Sesungguhnya Allah Maha mengetahui lagi Maha Mengenal." (Departemen Agama Rl, 2001:1109)

Dalam islam ada beberapa hal yang dilarang ketika berinvestasi, yaitu 
unsur riba, maysir, gharar, syubhat dan haram (Satrio dalam Huda dan Heykal, 2010:191). Tujuan islam menganjurkan melakukan investasi yaitu untuk mencapai kebahagiaan dunia dan akhirat baik dimasa sekarang maupun dimasa yang akan datang, baik untuk generasi sekarang maupun generasi yang akan datang (Nafik, 2009: 70). Dengan adanya hal tersebut maka dalam melakukan investasi seorang muslim harus tetap mengingat Allah SWT.

Salah satu sarana investasi bagi investor muslim yaitu pasar modal syariah. Pasar modal syariah adalah pasar modal yang dijalankan dengan prinsip-prinsip syariah, setiap transaksi surat berharga di pasar modal dilaksanakan sesuai dengan ketentuan syariat Islam (Sutedi, 2011:29). Ada beberapa hal yang harus diperhatikan didalam pasar modal, antara lain kehalalan produk atau jasa, adanya kegiatan usaha yang spesifik, adanya mekanisme bagi hasil yang baik dan adil serta mekanisme pasar berjalan dengan wajar dan disertai prinsip kehatihatian dari investor (Pontjowinoto, 2003: 39).

Di pasar modal syariah diperdagangkan efek-efek yang didasarkan pada fatwa DSN-MUI, salah satu efek tersebut yaitu saham. Dalam islam saham menggunakan kombinasi akad musyarakah dan mudharabah baik secara terbuka maupun tertutup (Nafik, 2009:244). Pada sistem musyarakah, dua dua atau beberapa pihak menyetorkan modal dan ikut mengelola modal yang telah disetorkan. Sedangkan sistem mudharabah pihak yang menyetorkan modal tidak perlu ikut mengelola modal. Mudharabah tertutup adalah jenis mudharabah yang pemilik dananya tidak bisa dialihkan ke pihak lain. sedangkan mudharabah terbuka adalah jenis mudharabah yang kepemilikan dananya dapat dengan mudah dialihkan ke pihak lain karena penyertaan dibagi-bagi dalam bentuk saham sebagai bukti kepemilikan.

Untuk menggambarkan kinerja saham perusahaan maka dibentuklah indeks syariah. Di Indonesia indeks syariah yang pertama kali dibentuk yaitu Jakarta Islamic Index (JII). Dalam indeks tersebut terdiri dari 30 saham yang termasuk kategori syariah.

Sebelum mengambil keputusan investasi, seorang investor hari memperhatikan informasi yang sedang berkembang di pasar modal. Hal ini bertujuan agar investor tidak salah dalam mengambil keputusan investasi. Salah satu informasi yang baru-baru ini telah berdar yaitu adanya penerapan keputusan perubahan satuan perdagangan. Dalam keputusan tersebut disebutkan bahwa satuan perdagangan yang awalnya 500 lembar diubah menjadi 100 lembar per lotnya. Adanya penerapan keputusan ini tentu menimbulkan berbagai reaksi dari investor sehingga mempengaruhi keputusan investasi yang diambil. Apabila informasi tersebut dianggap memberikan sinya positif maka investor akan melakukan pembelian saham, tapi jika 
informasi tersebut memberikan sinya negatif maka investor akan melakukan penjualan saham.

Adanya reaksi jual atau beli dari investor tentu akan berpengaruh terhadap tingkat likuiditas saham. Secara umum Alexander dkk (1990) dalam Ferdian (2012: 47) mendefinisikan likuiditas sebagai kemampuan investor untuk menjual harta yang dimilikinya tanpa harus melakukan kelonggaran harta. Secara spesifik Koentin (1994) dalam Mulyana (2011) mendefinisikan likuiditas saham adalah mudahnya saham yang dimiliki seseorang dapat diubah menjadi uang tunai melalui mekanisme pasar modal. Semakin tinggi likuiditas saham maka semakin tinggi minat investor untuk memiliki saham tersebut (Mulyana, 2011).

Untuk melihat tingkat likuiditas saham dapat menggunakan beberapa proksi, salah satunya dengan melihat volume perdagangan saham dan frekuensi transaksi saham.

Volume perdagangan saham merupakan jumlah saham yang diperdagangkan di bursa pada periode tertentu. Tingkat likuiditas saham dihitung dengan TVA (Trading Volume Activity). Perhitungan TVA dapat dilakukan dengan menggunakan rumus sebagai berikut:

$$
\text { TVA }=\frac{\text { jumlah volume saham } \mathrm{i} \text { yang diperdagangkan pada waktu } t}{\text { jumlah saham } \mathrm{i} \text { yang beredar di bursa pada waktu } \mathrm{t}}
$$

Semakin tinggi nilai TVA maka semakin likuid saham tersebut.

Frekuensi transaksi saham merupakan jumlah transaksi pada saham tertentu pada periode tertentu.
Perhitungan frekuensi transaksi saham menggunakan TFA (Transaction Frequency Activity). Untuk mencari nilai TFA dapat dilakukan perhitungan dengan rumus sebagai berikut:

TFA $=\frac{\text { jumlah frekuensi saham i pada waktu } t}{\text { jumlah frekuensi saham i per tahun }}$

Semakin tinggi nilai TFA maka semakin likuid saham tersebut.

\section{METODE PENELITIAN}

Penelitian ini menggunakan pendekatan kuantitatif yang menguji populasi atau sampel yang telah diambil secara random dan data yang telah diperoleh akan diuji dengan alat statistik untuk menguji hipotesis yang telah ditetapkan (Sugiyono, 2013:14)

\section{Devinisi Operasional Variabel}

1. Peristiwa penerapan keputusan perubahan satuan perdagangan

Peristiwa yang ada di pasar modal tentu akan menimbukan berbagai reaksi dari investor, baik itu positif maupun negatif. Salah satu peristiwa yang terjadi di pasar modal yaitu penerapan keputusan perubahan satuan perdagangan. Keputusan tersebut resmi diberlakukan pada 6 Januari 2014. Perubahan satuan perdagangan dari 500 lembar menjadi 100 lembar tentu menimbulkan reaksi dari investor yang berdampak pada keputusan investasi yang diambil.

2. Tingkat volume perdagangan saham 
Tingkat volume perdagangan saham merupakan jumlah saham i anggota JII yang diperdagangkan di bursa pada periode 5 hari sebelum dan 5 hari setelah penerapan keputusan perubahan satuan perdagangan.

3. Tingkat frekuensi transaksi saham

Tingkat frekuensi transaksi saham merupakan berapa kali saham i anggota JII ditransaksikan di bursa pada periode 5 hari sebelum dan 5 hari setelah penerapan keputusan perubahan satuan perdagangan.

\section{Jenis dan Sumber Data}

Dalam penelitian ini data yang digunakan adalah data sekunder yang diperoleh dari Bursa Efek Indonesia dengan mengakses www.idx.co.id, www.finance.yahoo.com dan sumber relevan lain baik dari buku literatur, seminar, penelitian terdahulu dan artikel.

Data yang diperlukan dalam penelitian ini antara lain, tanggal penerapan keputusan perubahan satuan perdagangan, volume perdagangan saham Jll pada periode 5 hari sebelum dan 5 setelah penerapan keputusan perubahan satuan perdagangan, frekuensi transaksi saham JII pada periode 5 hari sebelum dan 5 hari setelah penerapan keputusan perubahan satuan perdagangan serta data saham yang masuk dalam JII periode Desember 2013Mei 2014.

\section{Prosedur Pengumpulan Data}

Dalam mengumpulkan data ada beberapa tahap yang dilakukan dalam penelitian ini, yaitu:

1. Dilakukan studi kepustakaan dengan mengumpulkan pustakapustaka yang mendukung penelitian ini baik dari literatur maupun penelitian terdahulu dan dari kajian ilmiah.

2. Mengumpulkan data sekunder yang diperlukan dalam penelitian ini.

\section{Teknik Analisis Data}

Metode yang digunakan dalam penelitian ini adalah event studi, dimana dalam metode tersebut melakukan pengamatan mengenai pergerekan suatu variabel akibat adanya suatu peristiwa (Peterson (1989) dalam Wismar'ein, 2004). Langkah-langkah yang dilakukan dalam teknik analisis data sebagai berikut:

1. Menghitung nilai volume perdagangan, dapat dilakukan dengan beberapa tahapan yaitu:

a. Menghitung actual trading volume activity, dengan rumus sebagai berikut:

TVA $=\frac{\text { jumlah volume saham } \mathrm{i} \text { yang diperdagangkan pada waktu } \mathrm{t}}{\text { jumlah saham } \mathrm{i} \text { yang beredar di bursa pada waktu } \mathrm{t}}$

b. Menghitung expected trading volume activity, dengan rumus sebagai berikut:

Expected TVA $=\frac{\text { total volume semua emiten pada waktu } t}{\text { total lembar saham yang beredar di pasar pada waktu } \mathrm{t}}$

c. Menghitung adnormal trading volume activity, dengan rumus sebagai berikut:

Abnormal TVA = actual TVA - expected TVA 
2. Menghitung nilai frekuensi transaksi saham, dalam perhitungannya diberlakukan hal yang sama seperti perhitungan volume perdagangan saham yaitu:

a. Menghitung actual transaction frequency activity, dengan rumus sebagai berikut:

TFA $=\frac{\text { jumlah frekuensi saham i pada waktu } t}{\text { jumlah frekuensi saham i per tahun }}$

b. Menghitung expected transaction frequency activity, dengan rumus sebagai berikut:

Expected TFA $=\frac{\text { total frekuensi semua saham pada waktu } t}{\text { total frekuensi semua sahan per tahun }}$

c. Menghitung abnormal transaction frequency activity, dengan rumus sebagai berikut:

Abnormal TFA $=$ actual TFA - expected TFA

3. Merumuskan hipotesis terhadap trading volume activity dan transaction frequency activity.

a. Hipotesis untuk trading volume activity

$\mathrm{H}_{0}: \mathrm{x}_{1}=\mathrm{x} 2$, artinya terdapat perbedaan nilai TVA yang tidak signifikan antara sebelum dan setelah penerapan keputusan perubahan satuan perdagangan.

$\mathrm{H}_{1}: \mathrm{x} 1 \neq \mathrm{x} 2$, artinya terdapat perbedaan nilai TVA yang signifikan antara sebelum dan setelah penerapan keputusan perubahan satuan perdagangan.

b. Hipotesis untuk transaction frequency activity
$\mathrm{H}_{0}: \mathrm{x} 1=x 2$, artinya terdapat perbedaan nilai TFA yang tidak signifikan antara sebelum dan setelah penerapan keputusan perubahan satuan perdagangan.

$\mathrm{H}_{1}: \mathrm{xl} \neq \mathrm{x} 2$, artinya terdapat perbedaan yang signifikan antara sebelum dan setelah penerapan keputusan perubahan satuan perdagangan.

4. Mengukur tingkat signifikansi dari uji hipotesis yaitu $5 \%$

5. Membandingkan thitung dengan tingkat signifikansi

a. Jika thitung $\geq 5 \%$, maka $\mathrm{HO}$ diterima

b. Jika thitung $\leq 5 \%$, maka $\mathrm{HO}$ ditolak

Uji statistik penelitian ini menggunakan program SPSS versi 16.0. Sedangkan untuk menguji tingkat perbedaan kedua sampel menggunakan Paired Samle T-Test.

\section{HASIL DAN PEMBAHASAN}

Setelah melakukan perhitungan data penelitian dapat dijelas mengenai analisis statistik deskriptif terhadap abnormal trading volume activity sebagai berikut:

Tabel 1.

Statistik Deskripstif Abnormal Trading Volume Activity

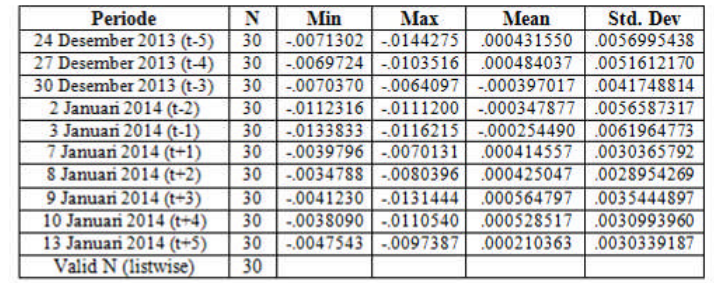

Sumber: output SPSS 16 (data diolah, 2014) 
Berdasarkan tabel diatas dapat dilihat bahwa selama periode pengamatan, abnormal trading volume activity lebih kecil dari standart deviasai. Hal ini berarti bahwa selama periode pengamatan terjadi penyimpangan nilai abnormal trading volume activity yang semakin besar terhadap nilai rata-rata.

Selain deskriptif mengenai abnormal trading volume activity, juga dapat dijelaskan mengenai analisis statistik deskriptif terhadap abnormal transaction frequency activity sebagai berikut:

Tabel 2.

Statistik Deskriptif Abnormal Transaction Frequency Activity

\begin{tabular}{|c|c|c|c|c|c|}
\hline Periode & $\mathrm{N}$ & Min & Max & Mean & Std. Dev \\
\hline 24 Desember $2013(t-5)$ & 30 & -.0026714 & .0107393 & .000612080 & .0036676186 \\
\hline 27 Desember $2013(t-4)$ & 30 & -.0028571 & .0114574 & .000248930 & .0031540397 \\
\hline 30 Desember $2013(t-3)$ & 30 & -.0039606 & .0129618 & .000057217 & .0039058138 \\
\hline 2 Januari $2014(t-2)$ & 30 & -.0037720 & .0154615 & .000808930 & 004170 \\
\hline 3 Januari $2014(t-1)$ & 30 & -.0047485 & .0150406 & .000162890 & .0050696113 \\
\hline 7 Januari $2014(t+1)$ & 30 & -.0009863 & .0038974 & -.000055327 & .0010525771 \\
\hline 8 Januari $2014(t+2)$ & 30 & -.0011649 & .0054256 & .000172193 & .0016508862 \\
\hline 9 Januari $2014(t+3)$ & 30 & -.0014895 & .0134435 & .000474947 & .0029130424 \\
\hline 10 Januari $2014(t+4)$ & 30 & -.0012407 & .0057813 & .000350830 & .0017548829 \\
\hline 13 Januari $2014(t+5)$ & 30 & -.0029954 & .0141587 & .000446857 & .0043805852 \\
\hline & & & & & \\
\hline
\end{tabular}

Sumber: output SPSS 16 (data diolah, 2014)

Berdasarkan tabel diatas dapat dilihat bahwa rata-rata transaction frequency activity lebih kecil dari standart deviasi. hal ini menunjukkan bahwa selama periode pengamatan terjadi penyimpangan nilai abnormal transaction frequency activity yang semakin besar terhadap nilai rata-rata.

Setelah melakukan uji statistik paired sample t-test diperoleh hasil sebagai berikut:

Tabel 3.

Hasil Uji Statistik Paired Sample T-Test Pada Average Abnormal TVA

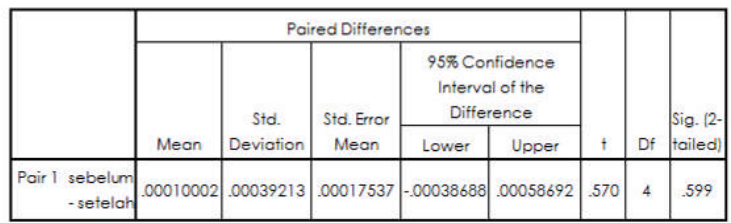

Sumber: output SPSS 16 (data diolah, 2014) Berdasarkan uji statistik diatas dapat dilihat bahwa nilai probabilitas lebih besar dari $5 \%$, yaitu sebesar 0.599 . Hal ini berarti bahwa terdapat perbedaan nilai average abnormal trading volume activity yang tidak signifikan antara sebelum dan setelah penerapan keputusan perubahan satuan perdagangan. Nilai positif pada rata-rata AATVA mencerminkan bahwa adanya peningkatan volume saham yang diperdagangkan oleh investor selama periode pengamatan.

Selain melakukan uji paired sample t-test terhadap abnormal trading volume activity, dalam penelitian ini juga dilakukan uji paired sample t-test terhadap abnormal transaction frequency activity dan diperoleh hasil sebagai berikut:

Tabel 4.

Hasil Uji Statistik Paired Sample T-Test Pada Average Abnormal TFA

\begin{tabular}{|c|c|c|c|c|c|c|c|c|}
\hline & \multicolumn{5}{|c|}{ Poired Differences } & \multirow[b]{3}{*}{+} & \multirow[b]{3}{*}{ of } & \multirow{3}{*}{$\begin{array}{l}\text { Sig. } 12 \\
\text { tailed }\end{array}$} \\
\hline & \multirow[b]{2}{*}{ Mean } & \multirow{2}{*}{\begin{tabular}{c|} 
Std. \\
Deviation
\end{tabular}} & \multirow{2}{*}{$\begin{array}{l}\text { Std. Error } \\
\text { Mean }\end{array}$} & \multicolumn{2}{|c|}{$\begin{array}{l}95 \% \text { Confidence } \\
\text { Interval of the } \\
\text { Difference }\end{array}$} & & & \\
\hline & & & & Lower & Upper & & & \\
\hline $\begin{array}{l}\text { air Sebelum } \\
\text {-setelah }\end{array}$ & & 000507195 & 00226825 & 10751 & .00018438 & -1.96 & & .121 \\
\hline
\end{tabular}

Sumber: output SPSS 16 (data diolah, 2014) Berdasarkan tabel diatas dapat dilihat bahwa nilai probabilitas yang dihasilkan lebih besar dari 5\%, yaitu sebesar 0.121. Hal ini menunjukkan bahwa terjadi perbedaan nilai average abnormal transaction frequency activity antara sebelum dan setelah penerapan 
keputusan perubahan satuan perdagangan. Nilai negatif dari rata-rata AATFA mencerminkan adanya tindakan investor lama untuk menghambat masuknya investor baru ke pasar modal. Tentu hal ini bertolak belakang dengan prinsip syariah yang menyebutkan bahwa islam memberikan kebebasan bagi umatNya untuk melakukan transaksi (Najmudin, 2011:179).

Adanya perbedaan nilai average abnormal TVA dan average abnormal TFA selama periode pengamatan tidak disebabkan karena adanya penerapan keputusan perubahan satuan perdagangan. Perbedaan tersebut terjadi karena adanya faktor lain yang lebih signifikan pengaruhnya tehadap average abnormal TVA dan average abnormal TFA.

\section{SIMPULAN}

Simpulan yang dapat diambil dari penelitian ini yaitu, pertama terdapat perbedaan nilai TVA yang tidak signifikan antara sebelum dan setelah penerapan keputusan perubahan satuan perdagangan. Hal ini didasarkan pada hasil uji statistik yang menghasilkan nilai probabilitas lebih besar dari 5\%, yaitu sebesar 0.599. Kedua, terdapat perbedaan nilai TFA yang tidak signifikan antara sebelum dan setelah penerapan keputusan perubahan satuan perdagangan. Hal ini berdasarkan hasil uji statistik yang menyebutkan bahwa nilai probabilitas lebih besar dari 5\%, yaitu sebesar 0.121 . Jadi penerapan keputusan perubahan satuan perdagangan berdampak tidak signifikan terhadap TVA dan TFA untuk saham yang tergabung adalam JII pada periode Desember 2013Mei 2014

Saran yang direkomendasikan setelah melakukan penelitian ini adalah:

1. Bagi investor, harus lebih proaktif agar mendapatkan informasi yang sedang beredar di pasar modal sehingga dapat dijadikan pertimbangan dalam pengambilan keputusan investasi agar tidak salah mengambil suatu tindakan

2. Bagi emiten, dengan bergabungan suatu perusahaan di pasar modal maka perusahaan akan dengan mudah mendapatkan tambahan dana dari masyarakat.

3. Bagi peneliti yang akan datang, agar dapat mengembangkan penelitian ini dengan penambahan variabel, memperbanyak populasi serta memperpanjang periode pengamatan.

\section{DAFTAR PUSTAKA}

Bambang Riyanto. 2007. Dasar-Dasar Pembelanjaan Perusahaan. Yogyakarta: BPFE

Bursa Efek Indonesia. 2004. Studi tentang Investasi Syariah di Pasar Modal Indonesia. (Online) www.idx.co.id diakses pada 1 Oktober 2014

Bursa Efek Indonesia. 2007. Mengenal Pasar Modal. (Online) www.idx.co.id diakses pada 1 Oktober 2014

Bursa Efek Indonesia. 2010. Buku Panduan Indeks Harga Saham Bursa Efek 
Indonesia. (Online) www.idx.co.id diakses pada 27 Oktober 2014

Departemen Agama RI. 2001. Al-Quran dan Terjemahannya dengan Transliterasi Model Per Baris. Semarang: Asy Syifa'

Ferdian, Reza. 2012. Pengaruh Likuiditas Saham Dan Return On Equity (ROE) Perusahaan Terhadap Tingkat Pengembalian Saham. Bandung: Universitas Widyatama (Online) www.widyatama.ac.id diakses pada 24 September 2014

Hartono, Jogiyanto. 2013. Teori Portofolio dan Analisis Investasi. Edisi Kedelapan. Cetakan Pertama. Yogyakarta: BPFE

Huda, Nurul dan Muhammad Heykal. 2010. Lembaga Kevangan Islam: Tinjauan Teoritis Dan Praktis. Jakarta: Prenada Media Group

Mulyana, Deden. 2011. Analisis Likuiditas Saham Serta Pengaruhnya Terhadap Harga Saham Pada Perusahaan Yang Berada Pada Indeks LQ-45 Di Bursa Efek Indonesia. Volume 4, No. 1 Jurnal Magister Manajemen

Nafik, Muhammad. 2009. Bursa Efek dan Investasi Syariah. Jakarta: Serambi IImu Semesta

Najmudin. 2011. Manajemen Keuangan Dan Akuntansi Syar'iyyah Modern. Yogyakarta: Andi Offset

Pontjowinoto, Iwan P. 2003. Prinsip Syariah di Pasar Modal: Pandangan Praktisi. Jakarta: Modal Publikasi

Sugiyono. 2013. Metode Penelitian Pendidikan (Pendekatan Kuantitatif, Kualitatif, dan R\&D). Bandung: Alfabeta
Sukmaningrum, Puji Sucia. 2009. Reaksi Pasar Terhadap Pengumuman Penerbitan Obligasi Syariah Di Bursa Efek Indonesia. Skripsi tidak diterbitkan. Surabaya Fakultas Ekonomi dan Bisnis Universitas Airlangga

Sutedi, Adrian. 2011. Pasar Modal Syariah. Jakarta: Sinar Grafika

Tandelilin, Eduardus. 2001. Analisis Investasi Dan Manajemen Portofolio. Yogyakarta: BPFE 